\title{
Hydromagnetic Lubrication of a Rough Porous Parabolic Slider Bearing with Slip Velocity
}

\section{Patel ND ${ }^{1 *}$ and Deheri GM ${ }^{2}$}

${ }^{1}$ Science and Humanities Department, Hansaba College of Engineering \& Technology, Gujarat, India

${ }^{2}$ Department of Mathematics, Sardar Patel University, Vallabh Vidyanagar, Anand, Gujarat, India

\begin{abstract}
An investigation has been launched in to the performance of a rough porous parabolic slider bearing under the presence of a magnetic fluid lubricant. The bearing surfaces are assumed to be transversely rough and this random roughness of the bearing surfaces has been characterized by a random variable with non-zero mean, variance and skewness. The concerned stochastically averaged Reynold's equation is solved with appropriate boundary conditions to obtain the pressure distribution resulting in the calculation of load carrying capacity. Further, the friction, the position of centre of pressure and temperature rise has been calculated. The results show that the effect of magnetization characterized by the magnetization parameter induces an improvement in the steady state performance as compared to the traditional conventional lubricant case, in spite of the fact that the transverse roughness adversely affects the bearing system. Further, a comparison of this investigation with the case of plane inclined slider bearing indicates that the magnetization results in a higher load carrying capacity and reduced friction. Also, the negatively skewed roughness and variance (-ve) enhance the already increased load carrying capacity due to magnetization.
\end{abstract}

Keywords: Parabolic slider; Roughness; Porosity; Magnetic fluid; Pressure; Load carrying capacity

\section{Introduction}

Basically, slider bearings are designed for supporting the transverse load in engineering systems. Bearing performance characteristics for various film shapes has been analyzed [1-3]. In order to improve the lubricating performance, applying the couple stress fluid model many investigations concerning the fluid film lubrication have been conducted. From the studies of squeeze film performance characteristics in finite plates by Ramanaish [4] in partial journal bearings by Lin [5]. It was found that the use of couple stress fluids increased the load carrying capacity and lengthened the response time of squeeze film action. In view of the discussions of journal bearings by Mokhiamer et al. [6] and Lin [5,7,8] and slider bearings by Ramanaish [9] and Lin [10]. It has been concluded that the effects of couple stresses reduce the friction parameter and result in longer bearing life. Lin [10] analyzes the effects of couple stress on the steady state performance of wide parabolic shaped slider bearing in accordance with Stokes microcontinuum theory. It was found that the couple stress effect signified an improvement in the steady state performance. Bayrakçeken [11] studied an infinitely wide lubricated slider bearing consisting of connected surfaces with third grade fluid as lubricant. Interest in fluids with strong magnetic properties has developed in recent years in connection with bearing design in technical applications. Significant progress has been made in the domain of nano scale science and technology during the last few years. Thus the use of magnetic fluid in lubrication of bearing system gets additional importance come nano scent point of view. Magnetic fluid which consists of colloidal magnetic nano particles dispersed with the aid of surfactants in a continuous career phase is a typical hybrid of soft material and the nano particles. The average diameter of the dispersed particles ranges from 5 to 10 $\mathrm{nm}$. The ferrofluid contain enormous magnetic nano particles in the fluid and hence can be influenced by either parallel or perpendicular magnetic field.

Agrawal [12] discussed the performance of a plane inclined slider bearing with a ferrofluid lubricant and established that its performance was comparatively better than the corresponding bearing with a conventional lubricant. The investigation of Bhat and Patel [13] concerning the exponential slider bearing with a ferrofluid lubricant concluded that the magnetic fluid lubricant caused increased load carrying capacity while the friction remained unaltered. Further, the study of Bhat and Deheri [14] revealed that the magnetic field sharply increased the load carrying capacity of a squeeze film between porous annular disks. This analysis of Bhat and Deheri [14] was modified and developed by Bhat and Deheri [15] to analyze the performance of a porous composite slider bearing under the presence of a magnetic fluid lubricant.

By now it is establish that the roughness of the bearing surfaces tends to retard the motion of the lubricant and hence affecting the bearing system adversely. From this point of view Christensen and Tonder [1618] modified the approach of Tzeng and Saibel [19] to present a study on the effect of surface roughness on the performance of the bearing system. The following investigation made use of the modeling of surface roughness given by Christensen and Tonder [16-18]. The performance of a transversely rough slider bearing with squeeze film by magnetic fluid was analyzed by Deheri et al. [20] by taking various shapes in to consideration. It was found that the magnetic fluid induced an increase in the load carrying capacity although, the effect of transverse surface roughness was found to be adverse in general. This squeeze film performance in the case of longitudinal roughness was relatively better as compared to transversely rough slider bearing for a porous squeeze

*Corresponding author: Patel ND, Science \& Humanities Department, Hansaba College of Engineering \& Technology, Sidhpur-384151 Gujarat, India, Tel: +91 2767 224855; E-mail: nitinpatel.gen@hcet.gtc.ac.in

Received April 02, 2014; Accepted May 23, 2014; Published June 06, 2014

Citation: Patel ND, Deheri GM (2014) Hydromagnetic Lubrication of a Rough Porous Parabolic Slider Bearing with Slip Velocity. J Appl Mech Eng 3: 143. doi:10.4172/2168-9873.1000143

Copyright: (C) 2014 Patel ND, et al. This is an open-access article distributed under the terms of the Creative Commons Attribution License, which permits unrestricted use, distribution, and reproduction in any medium, provided the original author and source are credited. 
film formed by a magnetic fluid as investigated by Deheri et al. [21]. Nanduvinamani et al. [22] dealt with the effect of couple stress and surface roughness on the performance characteristics of hydrodynamic lubrication of slider bearings with various film shapes. Recently Patel and Deheri [23] studied the Shliomis model based ferrofluid lubrication of a plane inclined slider bearing considering slip velocity. Here it was shown that the magnetization could minimize the adverse effect of surface roughness up to some extent when relatively small values of slip parameter are involved. Recently, Mobolaji and John [24] embarked upon a comparative study of pressure distribution and load carrying capacity of infinitely wide parabolic and inclined slider bearing. Here it has been proposed to study and analyze the hydro magnetic lubrication of a rough porous parabolic slider bearing with slip velocity.

\section{Analysis}

The geometry and configuration of the bearing system is displayed in Figure 1, which consists of a stator lying along $\mathrm{x}$-axes and having a porous matrix of uniform thickness $\mathrm{H}^{*}$ backed by a solid wall, and a parabolic shaped slider moving with a uniform velocity $U$ in $\mathrm{x}$-direction. The bearing has length $\mathrm{L}$ and breadth $\mathrm{B}$, with $\mathrm{L}<<\mathrm{B}$. The film thickness $\mathrm{h}$ is taken as

$$
h=h_{0}\left\{1+(1-m)\left(x^{2}-2 x\right)\right\}
$$

Where $h_{0}$ is the minimum value of $\mathrm{h}$.

The applied magnetic field $M$ is inclined and the inclination $\varphi$ can be determined as in the case of Bhat [25]. Following Bhat [25] and Prajapati [26] the magnitude of the magnetic field $M$ is represented by

$$
M^{2}=K x(L-x)
$$

$K$ being a quantity chosen to suit the dimensions of both sides and the strength of the magnetic field, such a magnetic field was used in [26] and [25]. According to [25] the basic equation governing the lubricant flow in the film region is

$$
\frac{\partial^{2} u}{\partial z^{2}}=\frac{1}{\zeta} \frac{\partial}{\partial x}\left(p-\frac{1}{2} \mu_{0} \bar{\mu} M^{2}\right)
$$

Where $\mathrm{u}, \zeta, \rho, \alpha^{2}, \bar{\mu}, \mathrm{p}$ and $\mu_{0}$ are respectively, the $\mathrm{x}$-component of the fluid film, fluid velocity, fluid density, material constant, magnetic susceptibility of the fluid particles, film pressure and the magnetic permeability of free space.

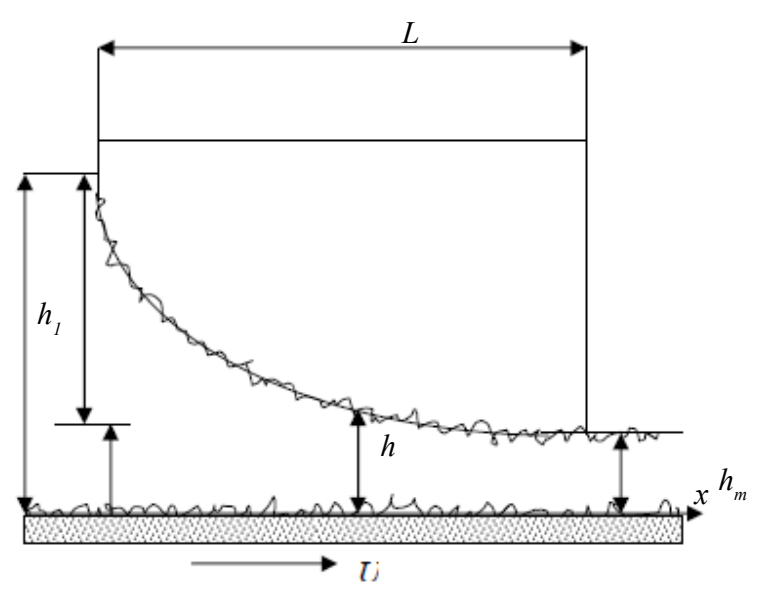

Figure 1: Parabolic Shaped Slider Bearing.
The above partial differential equation is solved under the conditions

$$
u=\left(\frac{1}{s} \frac{\partial u}{\partial z}\right)_{z=0}
$$

when $\mathrm{z}=0$, and $\mathrm{u}=\mathrm{U}$ when $\mathrm{z}=\mathrm{h}, \mathrm{s}$ being the slip constant. The value of $\mathrm{u}$ thus obtained is substituted in the integral form of the continuity equation for fluid film.

The bearing surfaces are assumed to be the transversely rough. Following the stochastical modeling of Christensen and Tonder [1618 ] the thickness $h(x)$ of the lubricant film is considered as

$$
h(x)=\bar{h}(x)+h_{s}
$$

Where $\bar{h}(x)$ the mean film thickness and $h_{s}$ is the deviation from the mean film thickness characterizing the random roughness of the bearing surfaces $h_{s}$ is assumed to be stochastic in nature and governed by the probability density function $f\left(h_{s}\right),-c \leq h, \leq c$, where $c$ is the maximum deviation from the mean film thickness. The mean $a$ standard deviation $\sigma$ and skewness $\varepsilon$, which is the measure of symmetry of the random variable $h_{s}$, are determined by the relationships,

$$
\begin{aligned}
& \alpha=E\left(h_{s}\right) \\
& \sigma^{2}=E\left[\left(h_{s}-\alpha\right)^{2}\right] \\
& \varepsilon=E\left[\left(h_{s}-\alpha\right)^{3}\right]
\end{aligned}
$$

where $\mathrm{E}$ is the expectancy operator given by

$$
E(R)=\int_{c}^{c} R f\left(h_{s}\right) d h_{s}
$$

while the probability density function is represented as

$$
f\left(h_{s}\right)=\left\{\begin{array}{rr}
35\left(c^{2}-h_{s}^{2}\right)^{3} / 32 c^{7}, & -c \leq h_{s} \leq c ; \\
0 & \text { otherwise. }
\end{array}\right\}
$$

With the usual assumptions of hydro magnetic lubrication assuming that the z-components of velocities of fluid in the film and porous regions are continuous at the surface $\mathrm{z}=0$, the Reynolds type equation is obtained as $[20,21,27]$.

$$
\begin{aligned}
& \frac{d}{d x}\left\{\left[\frac{12 k H^{*}+g(h)(4+s h)-3 \rho \alpha^{2} \bar{\mu} k s h^{2} M / \zeta}{(1+s h)\left[1-\rho \alpha^{2} \bar{\mu} M / 2 \zeta\right]}\right] \frac{d}{d x}\left(P-\frac{1}{2} \mu_{0} \bar{\mu} H M^{2}\right)\right\} \\
& =6 \zeta U \frac{d}{d x}\left(\frac{h(2+s h)-\rho \alpha^{2} \bar{\mu} k s M / \zeta}{1+s h}\right)
\end{aligned}
$$

Where

$$
g(h)=h^{3}+3 \alpha h^{2}+3\left(\alpha^{2}+\sigma^{2}\right) h+3 \sigma^{2} \alpha+\alpha^{3}+\varepsilon
$$

$\mathrm{k}$ being the permeability of porous matrix. The use of Equations (1), (2) and the dimensionless quantities

$$
\begin{aligned}
& X=\frac{x}{L}, \psi=\frac{k H^{*}}{h_{0}}, \bar{h}=\frac{h}{h_{0}}, \bar{s}=s h, \beta=\frac{\rho \alpha^{2} \bar{\mu} \sqrt{K L}}{\zeta}, P=\frac{h P}{\zeta U L}, \\
& \mu^{*}=\frac{\mu_{0} \bar{\mu} K L h_{0}^{2}}{\zeta U}, \bar{\gamma}=\frac{6 k}{h_{0}^{2}}, \bar{\alpha}=\frac{\alpha}{h_{0}}, \bar{\sigma}=\frac{\sigma}{h_{0}}, \bar{\varepsilon}=\frac{\varepsilon}{h_{0}}, W=\frac{h_{0}^{2} w}{\zeta U L^{2} B}, F=\frac{h_{0} f}{\zeta U L B}, \\
& Y=\frac{\bar{X}}{L}, \Delta T=\frac{g J \rho C h_{0}^{2}}{2 \mu U L} \Delta t
\end{aligned}
$$


In (9) leads to

$$
\frac{d}{d x}\left\{A \frac{d}{d x}\left[p-\frac{1}{2} \mu^{*} X(1-X)\right]\right\}=\frac{d B}{d X}
$$

where

$$
\begin{aligned}
& \bar{h}=\left\{1+(1-m)\left(X^{2}-2 X\right)\right\} \\
& g(\bar{h})=\bar{h}+3 \bar{\alpha}^{2}+3\left(\bar{\alpha}^{2}+\bar{\sigma}^{2}\right) \bar{h}+3 \bar{\sigma}^{2} \bar{\alpha}+\bar{\alpha}^{3}+\bar{\varepsilon} \\
& A=12 \psi+\frac{g(\bar{h})\left(4+3\left(\bar{\sigma}^{2}+\bar{\alpha}^{2}\right) \overline{s h}\right)}{\left(1+3\left(\bar{\sigma}^{2}+\bar{\alpha}^{2}\right) \overline{s h}\right)}
\end{aligned}
$$

And

$$
B=\frac{18\left(\bar{\sigma}^{2}+\bar{\alpha}^{2}\right) \bar{h}\left(2+3\left(\bar{\sigma}^{2}+\bar{\alpha}^{2}\right) \bar{s} \bar{h}\right)}{\left(1+3\left(\bar{\sigma}^{2}+\bar{\alpha}^{2}\right) \overline{s h}\right)}
$$

Since the pressure is negligible at the inlet and outlet of the bearing as compared to the inside pressure, one can resort to the boundary conditions $\mathrm{p}=0$ at $\mathrm{x}=0$, L. Solving Equation (11) under the boundary conditions the expression for non-dimensional pressure distribution comes out to be

$$
P=\frac{1}{2} \mu^{*} X(1-X)+\int_{0}^{1} \frac{B-C}{A} d X
$$

where

$$
C=\frac{\int_{0}^{1} \frac{B}{A} d X}{\int_{0}^{1} \frac{1}{A} d X}
$$

The load carrying capacity $\mathrm{W}$ of the bearing, friction force $\mathrm{F}$ on the slider and the $\mathrm{x}$-coordinate Xof the centre of pressure can be expressed in dimensionless form as

$$
\begin{aligned}
& W=\frac{h_{0}^{2} W}{\zeta U L^{2} B}=\frac{\mu^{*}}{12}-\int_{0}^{1} X \frac{B-C}{A} d X \\
& F=\frac{h_{0} F}{\zeta U L B}=\frac{1}{2} \int_{0}^{1}(m-1)(X-1) \bar{p} d X-\frac{1}{2[m(m-1)]^{1 / 2}} \ln \left|\frac{(m-1)-[m(m-1)]^{1 / 2}}{(m-1)+[m(m-1)]^{1 / 2}}\right|
\end{aligned}
$$

And

$Y=\frac{\bar{X}}{L}=\frac{1}{2 W}\left(\frac{\mu^{*}}{12}-\int_{0}^{1} X^{2} \frac{B-C}{A} d X\right)$

Lastly, following [3] the temperature rise $\Delta T$ in the dimensionless form is given by

$$
\Delta T=\frac{g J \rho C h_{0}^{2}}{2 \mu U L} \Delta t=\frac{\bar{F}}{H_{m}}
$$

Where

$$
H_{m}=\frac{\int_{0}^{1} h[g(h)]^{1 / 3} d x}{\int_{0}^{1}[g(h)]^{1 / 3} d x}
$$

\section{Results and Discussion}

A close look at the expression of load carrying capacity suggests that the roughness in general has an adverse effect whiles the magnetization increases the load carrying capacity.

Besides, taking roughness parameters to be equal to zero this study reduces to the performance of the corresponding smooth bearing system. Further, taking $\mu^{*}$ to be equal to zero and slip to be equal to zero this investigation essentially gives the performance of usual parabolic slider bearing. It is clearly observed that while the non-dimensional pressure increases by

$$
\frac{\mu^{*}}{2} X(1-X)
$$

the non-dimensional load carrying capacity enhances by

$$
\frac{\mu^{*}}{12}
$$

A closed scrutiny of the Reynolds's equation points out that the performance characteristics of a transversely rough parabolic slider bearing with film thickness $\mathrm{h}$ can be considered as equivalent to the corresponding identical smooth bearing with film thickness $[g(h)]^{1 / 3}$. The corresponding equivalent film profile $[g(\bar{h})]^{1 / 3}$ given in Figure 2 points to an increased film thickness throughout the bearing length. Further, the parabolic profile of the non-dimensional pressure distribution can be easily seen from Figure 3 .

The variation of load carrying capacity with respect to the magnetization parameter $\mu^{*}$ presented in Figures 4-6 indicates that

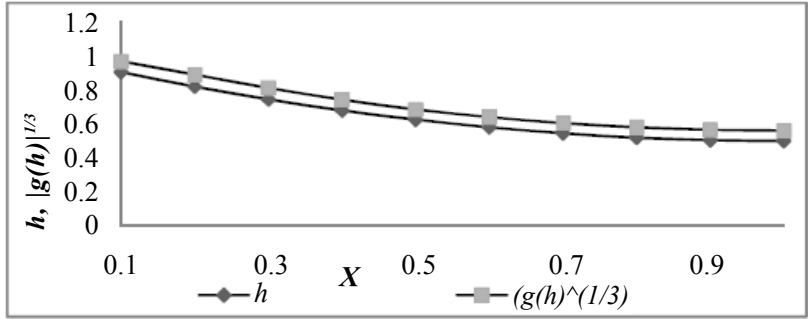

Figure 2: Variation of equivalent film profile $[g(h)]^{1 / 3}$.

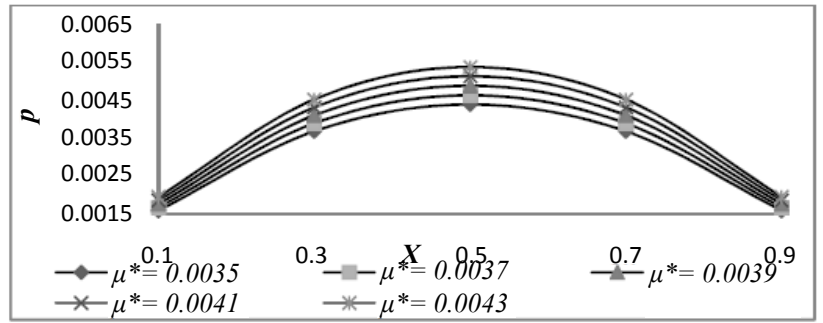

Figure 3: Variation of pressure with respect to $\mathrm{X}$ and $\mu$.

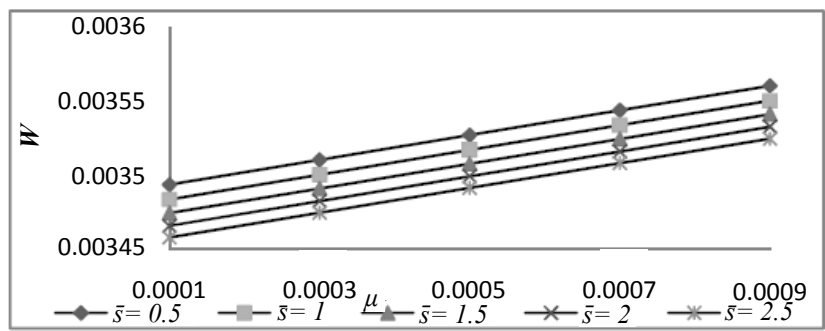

Figure 4: Variation of load carrying capacity with respect to $\mu^{*}$ and s. 
Citation: Patel ND, Deheri GM (2014) Hydromagnetic Lubrication of a Rough Porous Parabolic Slider Bearing with Slip Velocity. J Appl Mech Eng 3: 143. doi: $10.4172 / 2168-9873.1000143$

Page 4 of 8

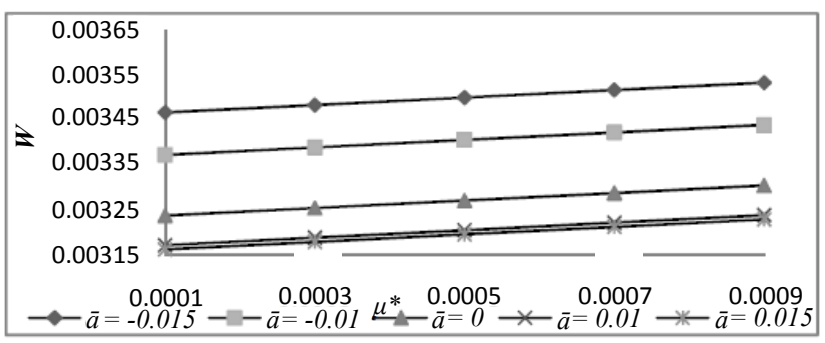

Figure 5: Variation of load carrying capacity with respect to $\mu^{*}$ and $\bar{\alpha}$.

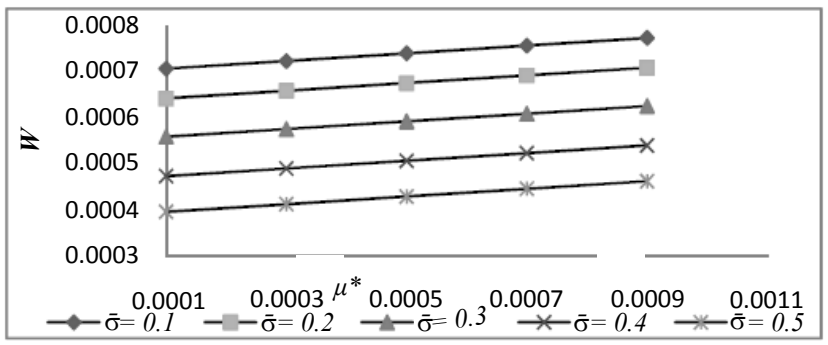

Figure 6: Variation of load carrying capacity with respect to $\mu^{*}$ and $\bar{\sigma}$.

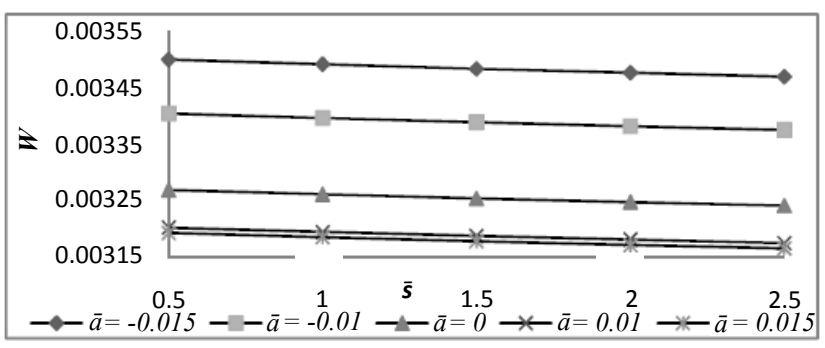

Figure 7: Variation of load carrying capacity with respect to $\bar{s}$ and $\bar{\alpha}$.

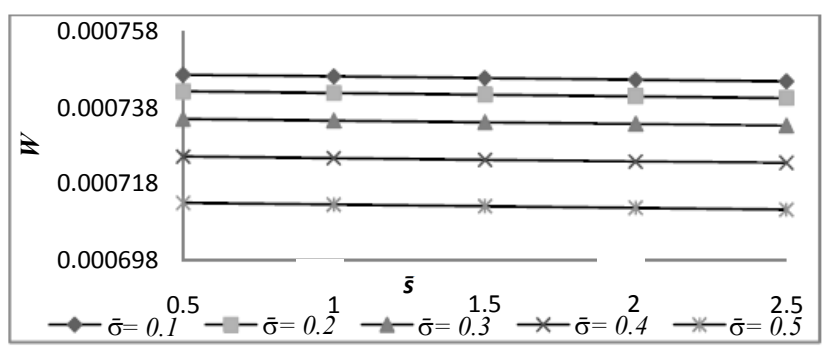

Figure 8: Variation of load carrying capacity with respect to $\bar{s}$ and $\bar{\alpha}$.

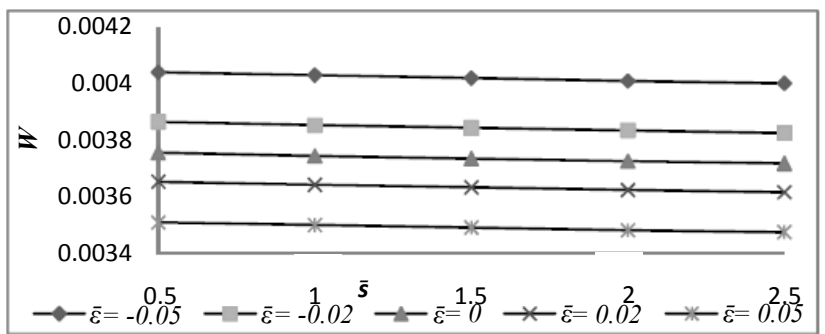

Figure 9: Variation of load carrying capacity with respect to $\bar{S}$ and $\bar{\varepsilon}$. magnetization increases the load carrying capacity. Further, the effect of higher values of variance on the load carrying capacity is negligible with respect to the magnetization parameter. It is found that the rate of increase in load carrying capacity is relatively more in the case of a slip coefficient.

Figures 7-10 present the effect of slip parameter on the distribution of load carrying capacity. It is clearly seen that the load carrying capacity decreases due to slip velocity. Also, it is seen that the effect of higher values of $\alpha$ on the distribution of load carrying capacity with respect to slip parameter is negligible.

The effect of roughness parameters are presented in Figures 11 and 12 . It is clearly observed that the load carrying capacity decreases sharply due to the standard deviation. Besides, skewness (+ve) decreases the load carrying capacity, while the load carrying capacity gets enhanced by the negatively skewed roughness. The trends of the load carrying capacity with respect to variance follow almost the paths of the skewness. Thus, the combined effect of negatively skewed roughness and variance (-ve) is significantly positive.

The profiles of the variation of friction presented in Figures 13-15 make it clear that the magnetization reduces the friction considerably.

The effect of slip parameter described in Figures 16-18 establishes that the friction gets reduced significantly due to the slip parameter

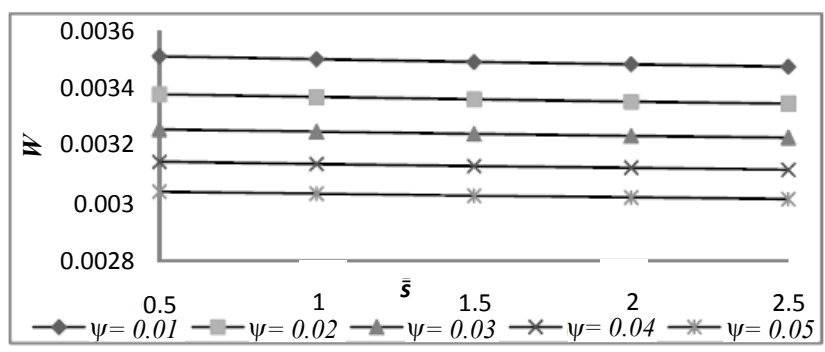

Figure 10: Variation of load carrying capacity with respect to $\bar{s}$ and $\psi$.

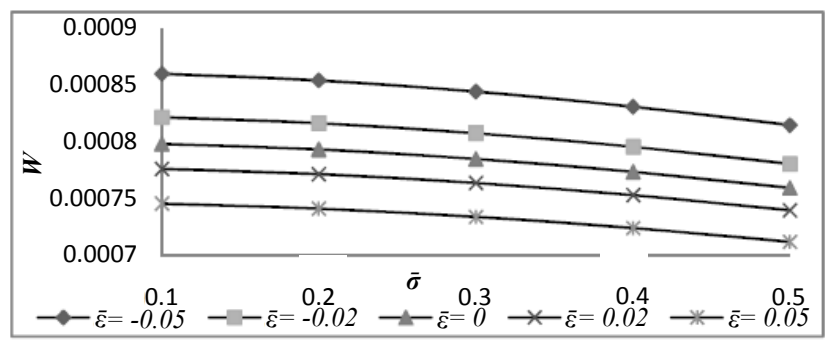

Figure 11: Variation of load carrying capacity with respect to $\bar{\sigma}$ and $\bar{\varepsilon}$.

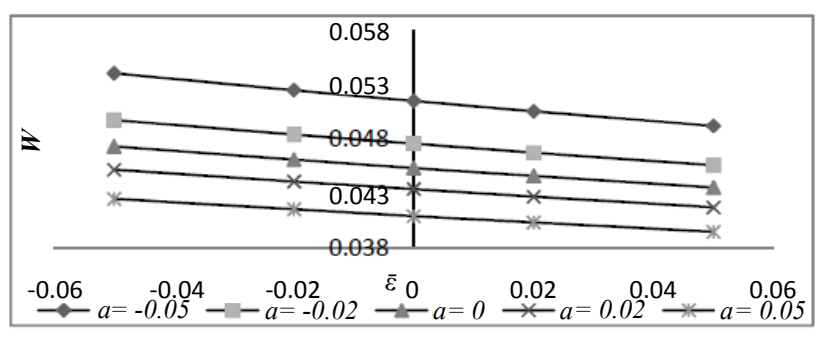

Figure 12: Variation of load carrying capacity with respect to $\bar{\varepsilon}$ and $\bar{\alpha}$. 
Citation: Patel ND, Deheri GM (2014) Hydromagnetic Lubrication of a Rough Porous Parabolic Slider Bearing with Slip Velocity. J Appl Mech Eng 3: 143. doi: $10.4172 / 2168-9873.1000143$

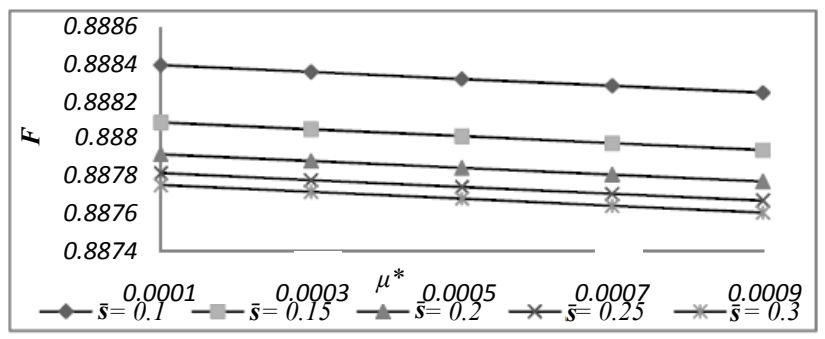

Figure 13: Variation of friction with respect to $\mu^{*}$ and $\bar{s}$.

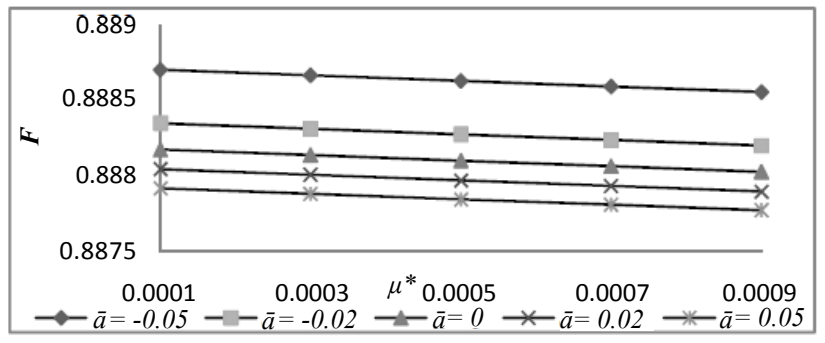

Figure 14: Variation of friction with respect to $\mu^{*}$ and $\bar{\alpha}$.

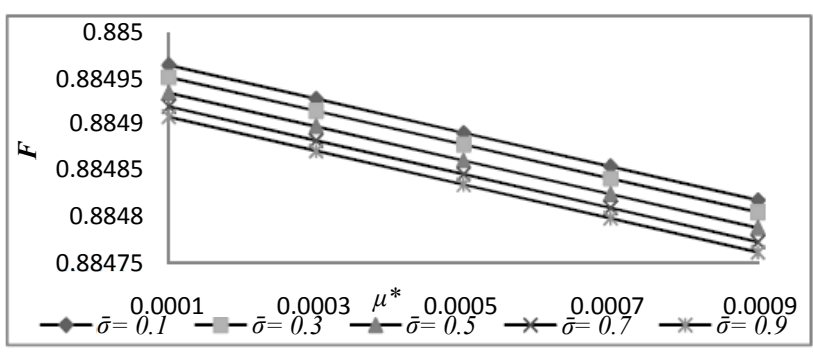

Figure 15: Variation of friction with respect to $\mu^{*}$ and $\bar{\sigma}$.

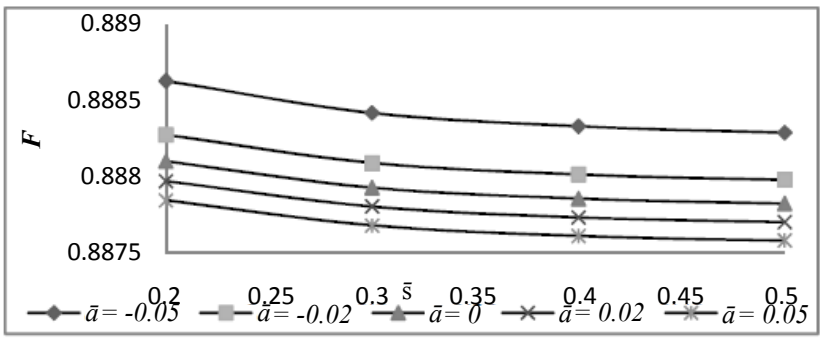

Figure 16: Variation of friction with respect to $\bar{s}$ and $\bar{\alpha}$.

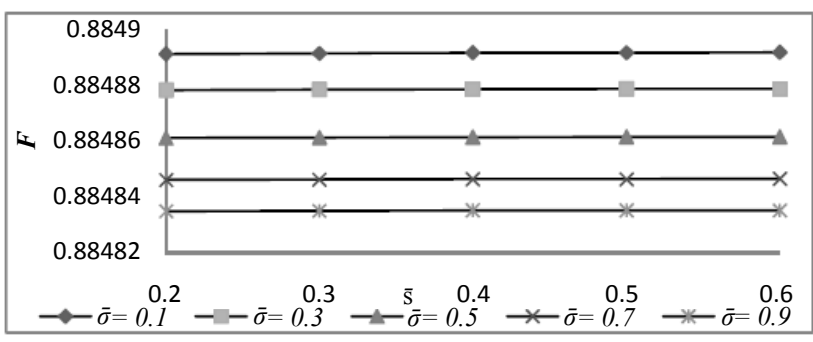

Figure 17: Variation of friction with respect to $\bar{s}$ and $\bar{\sigma}$.

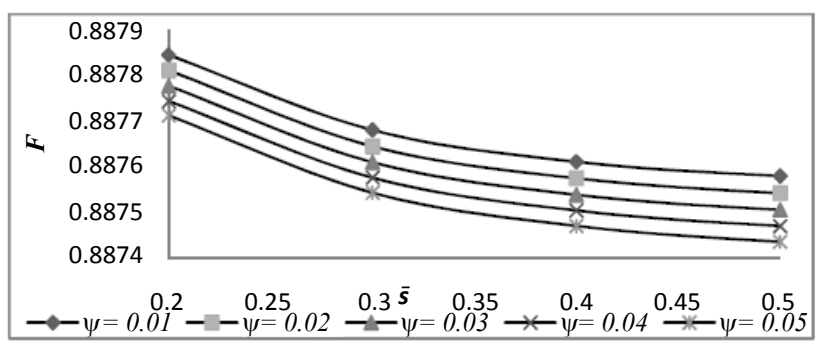

Figure 18: Variation of friction with respect to $\bar{s}$ and $\psi$.

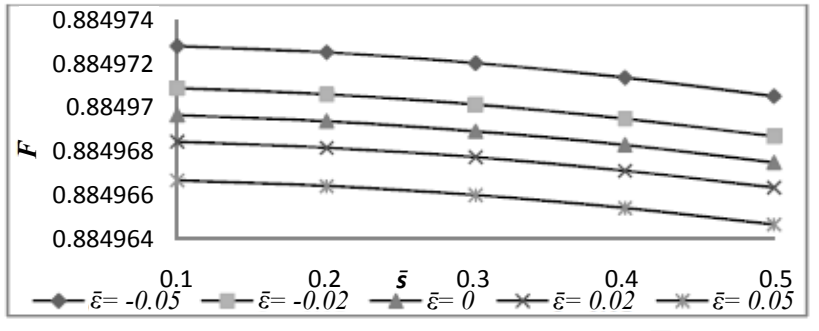

Figure 19: Variation of friction with respect to $\bar{\sigma}$ and $\bar{\varepsilon}$.

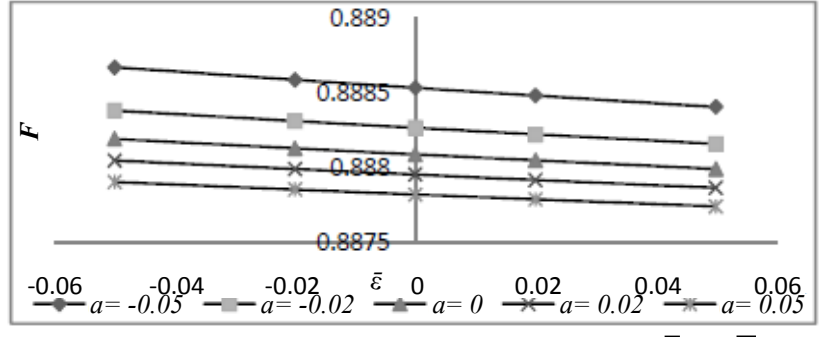

Figure 20: Variation of friction with respect to $\bar{\varepsilon}$ and $\bar{\alpha}$.

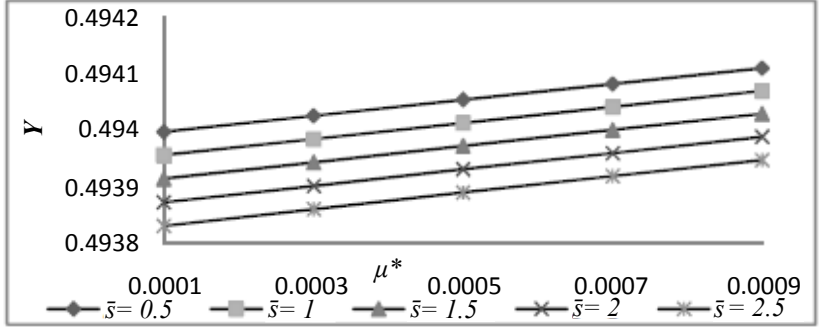

Figure 21: Variation of position of centre of pressure with respect to $\mu^{*}$ and $\bar{s}$.

and this decrease in friction is relatively less in the case of standard deviation.

Figures 19 and 20 suggest that the friction reduces due to the standard deviation. Further, negatively skewed roughness increases the friction while the friction decreases with respect to the positively skewed roughness. The variance follows the trends of skewness.

The fact that magnetization shifts the centre of pressure towards the outlet edge is clear from Figures 21-24.

This trend gets reversed in the case of slip parameter in the sense that the centre of pressure moves slowly towards the inlet edge as is evident from Figures 25-27. 
Citation: Patel ND, Deheri GM (2014) Hydromagnetic Lubrication of a Rough Porous Parabolic Slider Bearing with Slip Velocity. J Appl Mech Eng 3: 143. doi: $10.4172 / 2168-9873.1000143$

Page 6 of 8

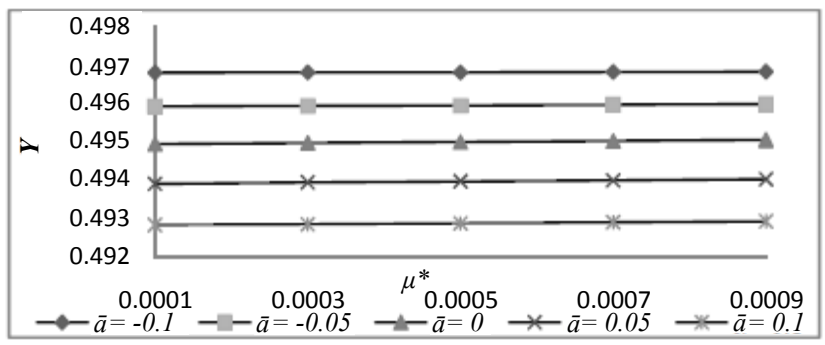

Figure 22: Variation of position of centre of pressure with respect to $\mu^{*}$ and $\bar{\alpha}$.

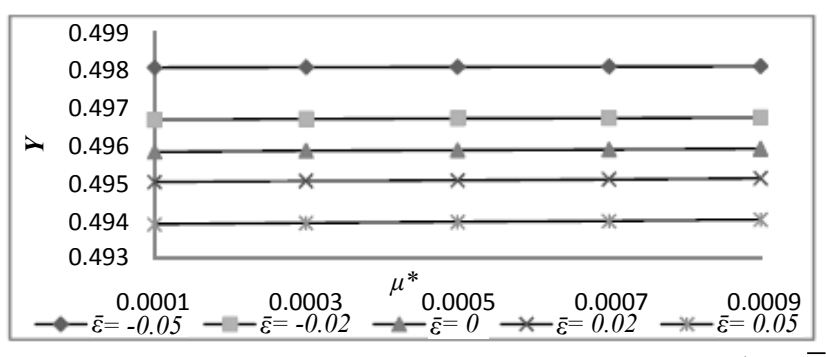

Figure 23: Variation of position of centre of pressure with respect to $\mu^{*}$ and $\bar{\varepsilon}$.

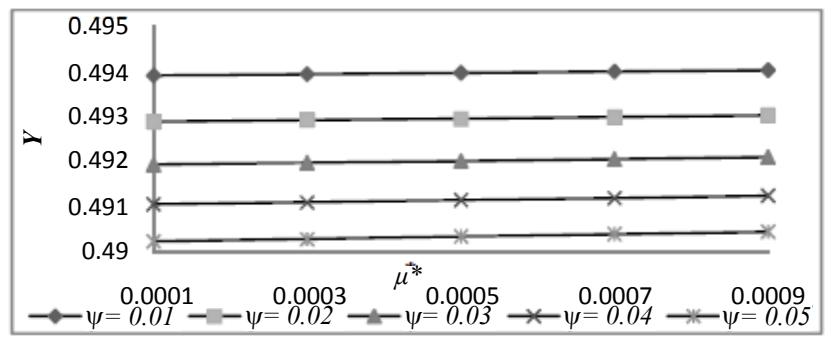

Figure 24: Variation of position of centre of pressure with respect to $\mu^{*}$ and $\psi$.

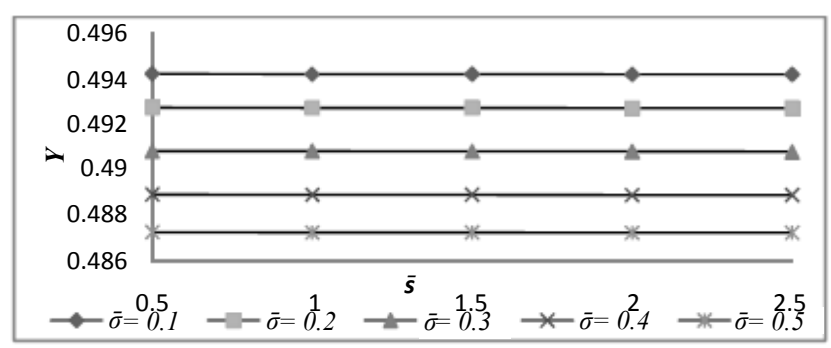

Figure 25: Variation of position of centre of pressure with respect to $\bar{s}$ and $\bar{\sigma}$.

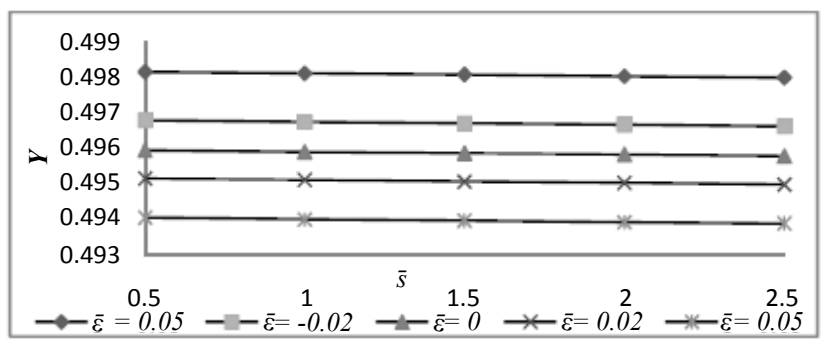

Figure 26: Variation of position of centre of pressure with respect to $\bar{S}$ and $\bar{\varepsilon}$.
Further, $\bar{\sigma}$ positively skewed roughness and variance (+ve) shift the centre of pressure towards the inlet edge, while negatively skewed roughness and variance (-ve) push the centre of pressure towards the outlet edge (Figures 28-30).

Figures 31-33 indicate that the temperature rise decreases sharply with respect to magnetization.

Lastly, Figures 34-36 make it clear that the temperature rise decreases with respect to the slip parameter and this decrease are negligible when considered with the case of standard deviation.

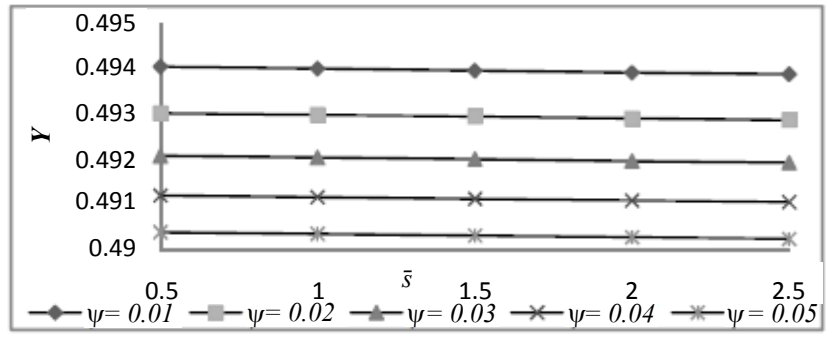

Figure 27: Variation of position of centre of pressure with respect to $\bar{s}$ and $\psi$

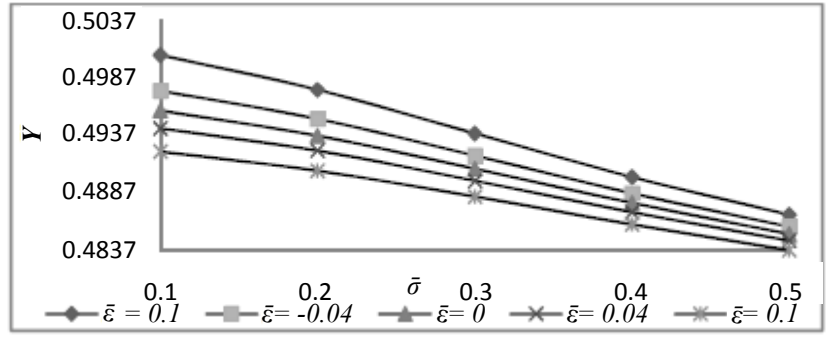

Figure 28: Variation of position of centre of pressure with respect to $\bar{\sigma}$ and $\bar{\varepsilon}$.

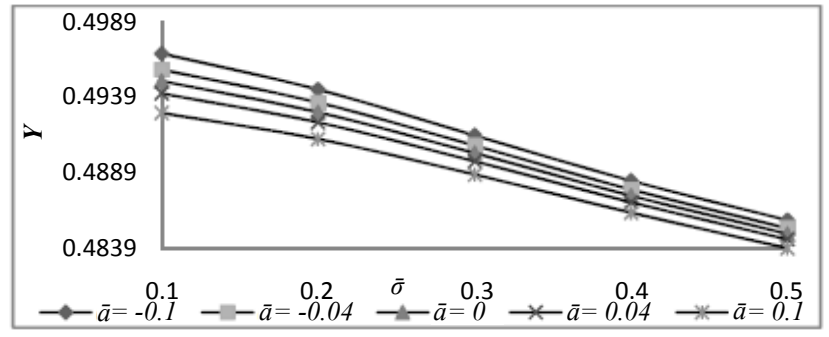

Figure 29: Variation of position of centre of pressure with respect to $\bar{\sigma}$ and $\bar{\alpha}$.

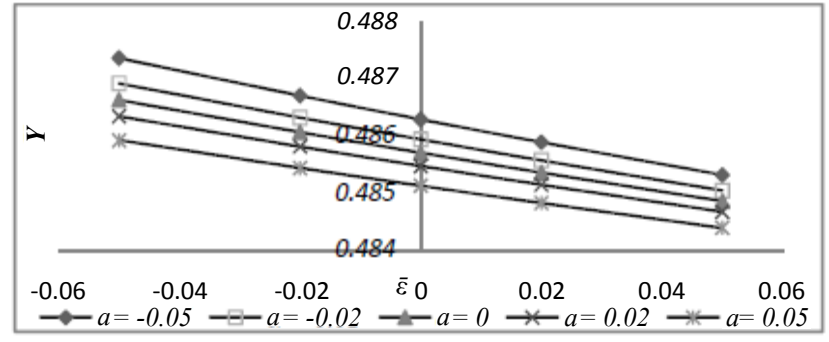

Figure 30: Variation of position of centre of pressure with respect to $\bar{\varepsilon}$ and $\bar{\alpha}$. 


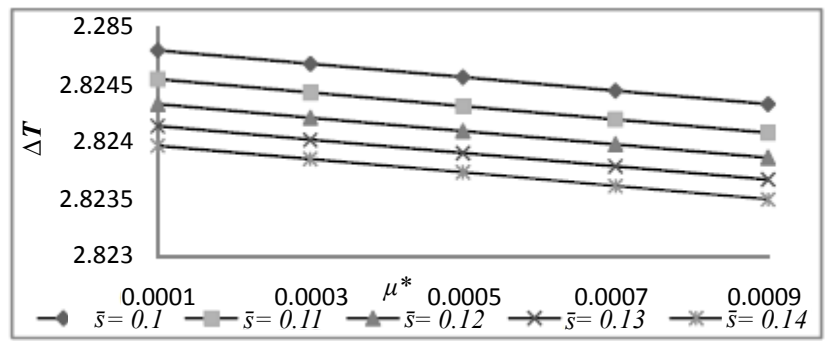

Figure 31: Variation of temperature rise with respect to $\mu^{*}$ and $\bar{s}$.

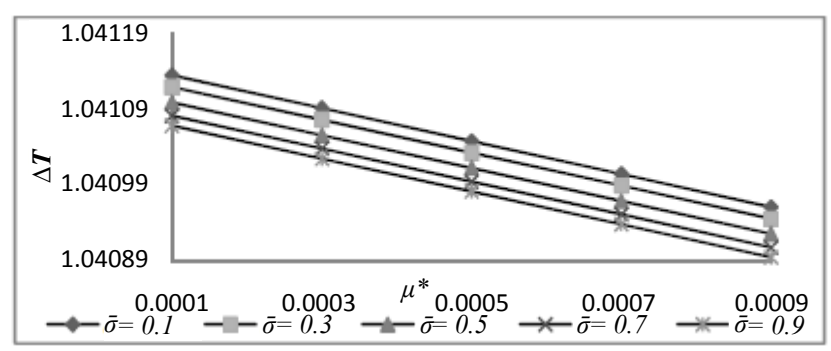

Figure 32: Variation of temperature rise with respect to $\mu^{*}$ and $\bar{\sigma}$.

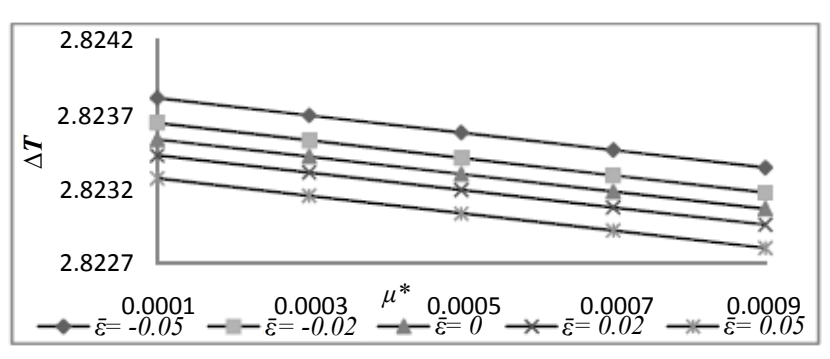

Figure 33: Variation of temperature rise with respect to $\mu^{*}$ and $\bar{\varepsilon}$.

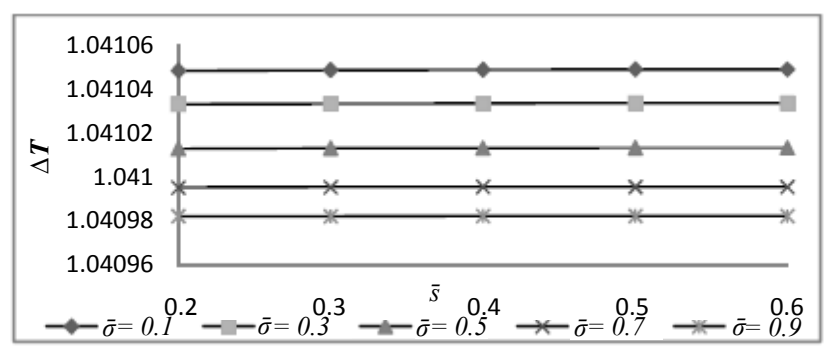

Figure 34: Variation of temperature rise with respect to $\bar{S}$ and $\bar{\sigma}$.

Some of the graphs drawn here tend to reveal that the positive effect of the magnetization parameter gets accelerated due to negatively skewed roughness and this effect becomes sharper when the lower values of slip parameter are involved. Moreover, variance (-ve) increases the positive effect of the magnetization parameter when lower values of porosity are involved.

\section{Conclusion}

The use of magnetic fluid lubricant not only improves the performance of the bearing system but also results in longer bearing life period. In addition this investigation asserts that the bearing can support a load even in the absence of flow. Moreover, this analysis

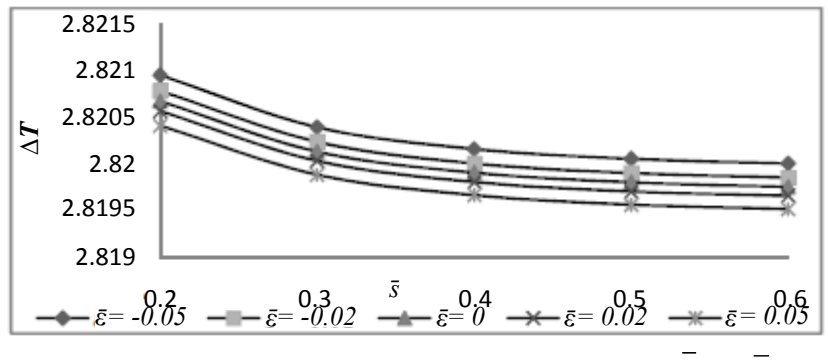

Figure 35: Variation of temperature rise with respect to $S$ and $\bar{\varepsilon}$.

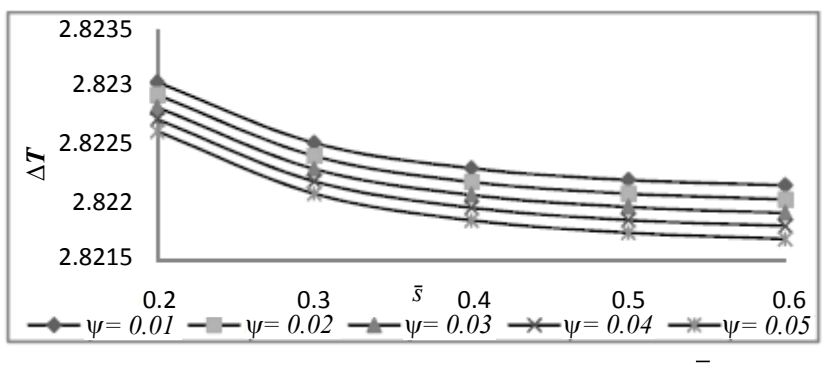

Figure 36: Variation of temperature rise with respect to $S$ and $\psi$.

confirms that the roles of variance and skewness are equally crucial from bearing design point of view. Besides, this study establishes that the roughness should be accounted for while designing the bearing system even if, the magnetic field strength is suitably chosen

\section{Nomenclature}

P Dimensionless pressure

U Velocity of slider

W Dimensionless load carrying capacity

$\mathrm{X} \quad \mathrm{X}$ coordinate of the centre of pressure

Y Dimensionless position of the centre of pressure

$\mathrm{h}_{0} \quad$ Fluid film thickness at $\mathrm{x}=0$

$\bar{s} \quad$ Dimensionless slip parameter

$\mathrm{H}^{*} \quad$ Thickness porous matrix

$\sigma \quad$ Standard deviation

$\varepsilon \quad$ Skewness

$\psi$ Porosity

$\varphi \quad$ Inclination of $\mathrm{M}$ with the $\mathrm{x}$-axis

$\mathrm{z} \quad$ Fluid viscosity

$\mathrm{t}$ Temperature rise

$\bar{\sigma} \quad$ Dimensionless standard deviation

$\bar{\alpha} \quad$ Dimensionless variance

$\bar{\varepsilon} \quad$ Dimensionless skewness

$\mu^{*} \quad$ Magnetization parameter in non-dimensional form

$\bar{\mu} \quad$ Magnetic susceptibility

$\mathrm{T} \quad$ Dimensionless temparature rise 
Citation: Patel ND, Deheri GM (2014) Hydromagnetic Lubrication of a Rough Porous Parabolic Slider Bearing with Slip Velocity. J Appl Mech Eng 3: 143. doi: $10.4172 / 2168-9873.1000143$

\section{Conflict of Interests}

We put on record that there is no conflict of Interests.

\section{References}

1. Cameron A (1966) The Principles of Lubrication, Longmans Green and Co. Ltd., London.

2. Pinkus O, Sternlicht B (1961) Theory of Hydrodynamic Lubrication, McGraw Hill, New York.

3. Hamrock BJ (1994) Fundamentals of Fluid Film Lubrication, McGraw-Hill, Inc., New York.

4. Ramanaish G (1979) Slider Bearings Lubricated by Fluids with Couple Stress, Wear 52: 27-36.

5. Lin JR (1997) b. Static Characteristics of Rotor Bearing System Lubricated with Couple Stress Fluids, Comput Struct 62: 175-184.

6. Mokhiamer U M, Crosby WA, El-Gamal HA (1999) A Study of a Journal Bearing Lubricated by Fluids with Couple Stress Considering the Elasticity of the Linear, Wear 224: 194-201.

7. Lin JR (1997) a. Effects of Couple Stresses on the Lubrication of Finite Journal Bearing, Wear 206: 171-178.

8. Lin JR (2001) Linear Stability Analysis of Rotor Bearing System: Couple Stress Fluid Model, Comput. Struct. 79: 801-809.

9. Ramanaish G (1979) Squeeze Films between Finite Plates Lubricated by Fluids with Couple Stress, Wear 54: 315-320.

10. Lin JR, Lu YM (2004) Steady state performance of wide parabolic shaped slider bearings with a couple stresses fluid, Journal of Marine Science and Technology 12: 239-246.

11. Bayrakçeken $H$, Yürüsoy $M$ (2006) Comparison of pressure distribution in inclined and parabolic slider bearings, Mathematical and Computational Applications 11: 65-73.

12. Agrawal VK (1986) Magnetic fluid based porous inclined slider bearing, Wear 107: $133-139$.

13. Bhat MV, Patel RR (1991) Analysis of an exponential porous slider bearing lubricated with magnetic fluid, J Eng Tech 6: 19-21.
14. Bhat MV, Deheri GM (1991) Squeeze film behavior in porous annular discs lubricated with magnetic fluid, Wear 151: 123-128.

15. Bhat MV, Deheri GM (1991) Porous composite slider bearing lubricated with magnetic fluid, Jap. J Appl Phys 30: 2513-2514.

16. Christensen, Tonder KC (1969) a.Tribology of rough surfaces: Stochastic models of hydrodynamic lubrication, SINTEF Report No. 10/69-18.

17. Christensen, Tonder KC (1969) b. Tribology of rough surfaces: parametric study and comparison of lubrication, SINTEF Report No. 22/69-18.

18. Christensen H, Tonder KC (1971) The Hydrodynamic lubrication of rough bearing surfaces of finite width, J Tribol 95: 166-172

19. Tzeng ST, Saibel E (1967) Surface roughness effect on slider bearing lubrication, Trans. ASME, J Lub Tech 10: 334-338.

20. Deheri GM, Andharia PI, Patel RM (2005) Transversely rough slider bearings with squeeze film formed by a magnetic fluid, International Journal of Applied Mechanics and Engineering 10: 53-76

21. Deheri GM, Andharia PI, Patel RM (2004) Longitudinally rough slider bearings with Squeeze film formed by a magnetic fluid, Industrial Lubrication and Tribology 56: 177-187.

22. Nanduvinamani NB, Fathima ST, Hiremath PS (2003) Hydrodynamic lubrication rough Slider bearings with couple stress fluids, Tribology International 36: 949959.

23. Patel ND, Deheri GM (2011) Shliomis model based ferrofluid lubrication of a plane inclined slider bearing with slip velocity, International Journal of Fluids Engineering 3: 311-324.

24. Mobolaji HO, John AA (2010) A comparative study of load carrying capacity and pressure distribution of infinitely wide parabolic and inclined slider bearings. Proceedings of the world congress on engineering $2 \mathrm{UK}$.

25. Bhat MV (2003) Lubrication with a magnetic fluid, Team Spirit (India) Pvt. Ltd.

26. Prajapati BL (1995) On certain theoretical studies in hydrodynamics and electro magneto hydrodynamics lubrication, Dissertation, S.P. University, Vallabh Vidyanagar.

27. Andharia PI, Gupta JL, Deheri GM (1998) Effect of longitudinal surface roughness on hydrodynamic lubrication of hyperbolic slider bearings, Proceedings of the National Academy of Sciences, India-Section A 68: 249256. 